\title{
LOS PERGAMINOS DE LA CASA DE AUSTRIA
}

Tesis de Licenciatura realizada bajo la dirección de la Doctora doña M. ${ }^{a}$ Luisa Cabanes Catalá, presentada en la Universidad de Alicante

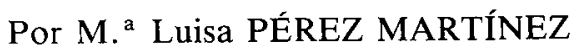

De entre los fondos documentales que se conservan en el Archivo Municipal de Alicante elegimos para la realización de nuestra Memoria de Licenciatura los instrumentos que corresponden al período de la casa de Austria. Se trata en su mayoría de documentos escritos sobre pergamino, si bien encontramos algunas cartas en papel, pero siempre son documentos originales.

La colección diplomática consta de 87 documentos, de los cuales algunos corresponden a monarcas anteriores a los Austrias, que hemos extraído de donde iban insertos. Va precedida de un estudio en el que se analizan los caracteres externos e internos y se hace una clasificación diplomática de los mismos, quedando agrupados en: privilegios, privilegios de confirmación, cartas, provisiones, sentencias, confirmación de un acuerdo del Consejo de Alicante y protesta.

Por motivos de limitación de espacio sólo podemos ofrecer las regestas de los instrumentos, sin indicar una serie de elementos como son: el tipo de escritura, color de la tinta, soporte, dimensiones, etc., que sí figuran en el trabajo original.

1382, octubre, 22, Valencia.

Juan I concede a la ciudad de Alicante que los jurados y prohombres de ésta $y$ de sus aldeas puedan disfrutar de todos y cada uno de los privilegios, libertades e inmunidades sobre los usos y las costumbres que poseían tiempo atrás.

B.-Inserto en el documento número 5 .

C.-A. M. A. Armario 1, libro 2, fol. 10 a $10 \mathrm{v}$.

E. -A. M. A. Armario 1, libro 3, fol. 176 a $177 \mathrm{v}$. 
1395, abril, 22, Barcelona.

Juan I confirma el privilegio otorgado por el rey Alfonso $X$ de Castilla a las ciudades de Orihuela y Alicante, consistente en recaudar el «ters de delme», siendo éste para la reparación, restauración y ornamentación de las iglesias.

B.-Inserto en el documento número 3.

E.-A. M. A. Armario 1, libro 3, fol. 55 a 56.

E 1 - A. M. A. Armario 1, libro 3, fol. 240 a 242v.

1399, octubre, 20, Zaragoza.

Martín el Humano aprueba y confirma el privilegio dado por su antecesor Juan I en 1395, por el cual se concede a las ciudades de Alicante y Orihuela el poder recaudar el «ters de delme», quedándose este dinero en la ciudad para la reparación, restauración y ornamentación de las iglesias.

B.--Inserto en el documento número 4.

E.-A. M. A. Armario 1, libro 3, fol. 55 a 56.

E 1 -A. M. A. Armario 1, libro 3, fol. 240 a 243.

1399, octubre, 31, Zaragoza.

Martín el Humano copia el privilegio dado por él en 1399 y por Juan I en 1395, por el cual se les concede a Alicante y a Orihuela el poder recaudar el «ters de delme" y gastárselo en la reparación, restauración y ornamentación de las iglesias.

C.-A. M. A. Copia del documento número 3.

E.-A. M. A. Armario 1, libro 3, fol. 55 a 56.

$\mathrm{E}_{1}$ - A. M. A. Armario 1, libro 3, fol. 240 a 243.

1510, agosto, 18, Monzón.

Fernando el Católico confirma el privilegio otorgado por su antecesor Juan I de 1385, por el cual ratifica a los prohombres y jurados de la ciudad de Alicante $y$ sus aldeas el disfrute de todos y cada uno de sus privilegios, gracias, prerrogativas y libertades.

B.--Inserto en el documento número 26.

E.-A. M. A. Armario 1, libro 3, fol. 175 a $179 \mathrm{v}$.

1514, junio, 8, Madrid.

Fernando el Católico, concede a Guillermo Guill, vecino de Alicante, el oficio de pesador de la balanza real y la harina, oficio que anteriormente lo realiza- 
ba Carlos Salort. Dicho oficio lo desempeñará de por vida y estará remunerado con un salario justo, beneficioso y con ganancias.

B.- Inserto en el documento número 8.

E.-A. M. A. Armario 1, libro 3, fol. $247 \mathrm{v}$ a 248 .

1520, abril, 30, La Coruña.

Carlos I concede el privilegio duradero por 5 años para que los oficios de justicia, jurados, mustasaf, cequiero y otros, sean todos de elección anual y encarga a Pedro Martínez de Vera que vacie las bolsas y haga nueva insaculación de todos los oficios de dicha ciudad, poniendo en éstas el numero acostumbrado de personas y dejando a un lado toda pasión por nadie.

A.-A. M. A. Caja 1, número 40.

1520 , mayo, 18 , Coruña.

Carlos I confirma el privilegio otorgado por su antecesor Fernando el Católico de 1514 a Guillermo Guill, consistente en poseer el oficio de pesador de la balanza real y de la harina.

A.-A. M. A. Caja 1, número 41.

E.-A. M. A. Armario 1, libro 3, fol. 247 a $248 \mathrm{v}$.

1527, julio.

Carlos I manda a los lugartenientes generales, a otros oficiales y a los súbditos del reino de Valencia que medien y pongan justicia entre los vecinos de Orcheta y los de Villajoyosa, ya que los primeros están sufriendo grandes agravios por los oficiales de Villajoyosa sin razones justificadas.

A.-A. M. A. Caja 5.

1528 , abril, 16, en el palacio real de Valencia.

Carlos I concede a los jurados y prohombres de la ciudad de Alicante el poder cargar 20.000 sólidos en censal.

A.-A. M. A. Caja 5.

1541, agosto, 25, Valladolid.

Felipe II, ante el pleito presentado por Ramón Ladró, síndico de Alicante, y Pedro Maça Olim, de la baronía de Castalla, sobre el curso de las aguas, se declara favorable a la propuesta del primero, alegando que ésta es beneficiosa para la ciudad de Alicante y declarando desierta la suplicación que concierne a la baronía de Castalla.

A.-A. M. A. Caja 5, número 7. 
1545, mayo, 21, Valencia.

Carlos I concede a la ciudad de Alicante el poder realizar la insaculación de sus cargos en dos bolsas. En la bolsa mayor se introducirán los nombres y apellidos de los que se presenten para realizar los oficios de justicias, jurados y mustasaf y en el saco menor, también con el nombre y los apellidos, para los oficios de cequiero, clavario y otros.

$$
\text { A.- A. M. A. Caja 2, número } 5 .
$$

1549, marzo, 12, Alicante.

Felipe II confirma y copia el privilegio dado por sus antecesores en los documentos de Juan I de 1395 y de Martín el Humano de 1399, por el cual concede a la ciudad de Alicante y de Orihuela el poder recaudar y quedarse el «ters de delme» y así utilizarlo para la restauración, reparación y ornamentación de las iglesias.

C.-A. M. A. Copia del documento número 4.

E.-A. M. A. Armario 1, libro 3, fol. 55 a $56 \mathrm{v}$.

$\mathrm{E}_{1}$ - A. M. A. Armario 1, libro 3, fol. 240 a $243 \mathrm{v}$.

1552, octubre, 18, Monzón.

Felipe II concede a la ciudad de Alicante, por petición del síndico Jerónimo Vallebrera, el que al ser ésta muy estéril en aguas, tanto naturales como pluviales, y no poder utilizar la poca que tiene para el riego, no pueden cultivar cereales, obligando a los que carguen mercaderias a que traigan los carros con cereales.

A.-A. M. A. Caja 2, número 9.

B.-Inserto en el documento número 29.

E.-A. M. A. Armario 1, libro 3, fol. $10 \mathrm{v}$ a $11 \mathrm{v}$.

$\mathrm{E}_{1}$.-A. M. A. Armario 1, libro 3, fol. $168 \mathrm{v}$ a 170.

E 2 -A. M. A. Armario 1, libro 3, fol. 190 a 192.

1556, octubre, 27, parroquia de san Pedro Fovet, Valencia.

Carlos I ante el proceso presentado por el mercader Diego de Vivanco, declara la sentencia favorable a Juan Ceva, puesto que se ha comprobado que la nave que traía el dinero para los salarios ha padecido sisa por el dicho Diego de Vivanco.

A.-A. M. A. Caja 2, número 10.

E.-A. M. A. Armario 1, libro 3, fol. $36 \mathrm{v}$ a 38.

1564, febremo, 7, Valencia.

Felipe II concede a Juan Lorenzo de Villarasa el poder otorgar a Lucas Ver- 
ger, notario y síndico de la ciudad de Alicante, licencia, autoridad y un contrato valedero para cuatro años para poder cargar censales en la ciudad de Alicante. A.-A. M. A. Caja 2, número 15.

1568, mayo, 29, Valencia.

Felipe II concede a Antonio Alfonso Pimentel, gobernador general de Valencia, autoridad para otorgar a Lucas Verger, notario de la ciudad de Alicante, licencia, permiso y facultad para cargar censales en Alicante, tanto ahora como en un futuro, por la cantidad de 1.350 libras.

A.-A. M. A. Caja 2, número 18.

1570, marzo, 18, Valencia.

Felipe II concede a Antonio Alfonso Pimentel, gobernador de Valencia, autoridad para dar licencia a Lucas Verger, notario y síndico de Aliante, para poder cargar censales en Alicante por la cantidad de 5.000 libras, de las cuales, 3.000 serán para comprar municiones y fortificar la ciudad y las otras 2.000 para comprar trigo.

A.-A. M. A. Caja 2, número 25.

1573, marzo, 10, parroquia de san Gil, Madrid.

Felipe II concede la sentencia favorable al síndico de la ciudad de Alicante, para poder cobrar un tributo que anteriormente le estaba vedado, consistente en el pago de éste por toda persona que viniese de tránsito a la ciudad y sus términos $y$ que ahora dicha cantidad permanecería en la ciudad.

A.-A. M. A. Caja 2, número 32.

E.-A. M. A. Armario 1, libro 3, fol. 118 a 120v.

1573, abril, 11, parroquia de san Gil, Madrid.

Felipe II ante el pleito presentado por el síndico de la ciudad de Alicante se declara a favor de que dicha ciudad pague el «derecho de coronación». Éste consistía en pagar 100 florines cuando se coronase a algún monarca y en este caso, Alicante los debía de pagar por la coronación de la reina Isabel, mujer de Felipe II.

A.-A. M. A. Caja 2, número 28.

E.-A. M. A. Armario 1, libro 3, fol. 115 a 117.

1573, junio, 9, Madrid.

Felipe II ante el pleito entre "la justicia prohibida» y «el derecho vedado», se declina a favor de la primera, defendida por el síndico de la ciudad de Alican- 
te, Jerónimo Ivars, y en contra del fiscal y procurador del patrimonio real, que defendía la segunda postura.

A.-A. M. A. Caja 2, número 28.

E.-A. M. A. Armario 1, libro 3, fol. 117 a $117 \mathrm{v}$.

1576, junio, 9, parroquia de san Nicolás, Valencia.

Felipe II ante el pleito presentado por Nicolás Desllor, síndico de Alicante, y Enrique de Palafoix, gobernador de Alicante, por el cual el primero denuncia al gobernador por ausentarse de su cargo sin dejar en su lugar a un alguacil que lo sustituyese, declara la sentencia favorable a Enrique de Palafoix ya que fue sustituido por Nicolás Pascual.

A.-A. M. A. Caja 2, n. ${ }^{\circ} 29$.

E.-A. M. A. Armario 1, libro 3, fol. 131v a 134.

1581, agosto, 9, parroquia de san Gil, Madrid.

Felipe II ante el pleito presentado por el síndico de Alicante y el fiscal y procurador del patrimonio real, declara la sentencia favorable a la ciudad de Alicante, por la cual se deberá reponer al real patrimonio de dicha ciudad de 15 en 15 años, contando a partir de 1550 dos quindemios para pagar dos laudemios y por lo tanto también en tiempo futuro deberá pagarse la cantidad establecida para dichos laudemios.

A.-A. M. A. Caja 5, n. ${ }^{\circ} 25$.

E.-A. M. A. Armario 1, libro 3, fol. 249 a $250 \mathrm{v}$.

\section{4}

1584, diciembre, 19, parroquia san Pedro, Valencia.

Felipe II ante el pleito presentado por Estéfano Martínez de Fresneda y Santiago Pascual Baesa, autoriza al gobernador general de Valencia, Francisco de Moncada, a intervenir en éste, dictando sentencia a favor del primero, concediéndole asi la gracia de poder recuperar unas posesiones en el tiempo de dos años.

A.-A. M. A. Caja 3, n. ${ }^{\circ} 2$.

1585, noviembre, 2, Monzón.

Felipe II concede a Tomás Vallebrera el oficio de racional de la ciudad de Alicante para el primer trienio próximo, para ejercerlo en su pleno uso y ejercicio del mismo, asi como también le otorga el salario, los lujos y las ganancias que dicho cargo conlleva.

A.-A. M. A. Caja 3, n. ${ }^{\circ} 4$.

1585, diciembre, 1, Monzón. 
Felipe II confirma el privilegio otorgado por sus antecesores Fernando el Católico de 1510 y Juan I de 1382, por el cual concede a la ciudad de Alicante que sus jurados y prohombres de ésta y de sus aldeas gocen de inmunidades, gracias, libertades y privilegios.

A.-A. M. A. Caja 3, n. ${ }^{\circ} 5$.

E.-A. M. A. Armario 1, libro 3, fol. 175 a 181.

1585, diciembre, 6, Binefar.

Felipe II confirma el privilegio otorgado por sus antecesores y por él en los documentos de Juan I de 1395, Martín el Humano de 1399 y Felipe II de 1549, por medio del cual concede a la ciudad de Alicante el poderse quedar el impuesto del «ters de delme» para la reparación, restauración y ornamentación de sus iglesias.

A.-A. M. A. Caja 3, n. ${ }^{\circ} 6$.

E.-A. M. A. Armario 1, libro 3, fol. $239 \mathrm{v}$ a $244 \mathrm{v}$.

1586, febrero, 10, Valencia.

Felipe II aprueba la enmienda presentada por el síndico de la ciudad de Alicante, Baltasar Vidania, consistente en que si algún vecino debiese alguna cantidad a esta ciudad no podrá desempeñar el cargo de consejero hasta que no pague sus deudas. Esto será duradero para siempre.

A.-A. M. A. Caja 3, n. ${ }^{\circ}$.

E.-A. M. A. Armario 1, libro 3, fol. $198 \mathrm{v}$ a $199 \mathrm{v}$.

1586, febrero, 16, Valencia.

Felipe II a petición del síndico de la ciudad de Alicante, Baltasar Vidania, vuelve a conceder el privilegio otorgado por él en 1550, al no haber sido renovado en las Cortes de 1563. En éste se obligaba a traer cereales a todos los que vinieran a Alicante a por mercancías.

A.-A. M. A. Caja 3, n. ${ }^{\circ} 8$.

E.-A. M. A. Armario 1, libro 3, fol. $168 \mathrm{v}$ a $171 \mathrm{c}$. blanco)

$\mathrm{E}_{1}$.-A. M. A. Armario 1, libro 3, fol. 190 a 193. (190 y 191 están en

1586, febrero, 20, Alcira.

Felipe II concede un aumento de los salarios al justicia y a su asesor, siendo éste de diez libras para el primero, con lo cual su sueldo será de 40 libras y para el asesor el aumento será de 5 libras, con lo cual ganará 20 libras.

A.-A. M. A. Caja 3, n. ${ }^{\circ} 9$.

E.-A. M. A. Armario 1, libro 3, fol. $251 \mathrm{v}$ a $252 \mathrm{v}$. 
1586, febrero, 20, Alcira.

Felipe II concedió a la ciudad de Alicante en las Cortes de Monzón, el poder sacar de Valencia madera, pero no marcó la cantidad. Es por ello por lo que el síndico de Alicante pide que para las necesidades de dicha ciudad sean 100 cargas anuales, pero el rey sólo concede 50, siempre y cuando la ciudad de Valencia quede cómodamente provehida de madera.

A.-A. M. A. Caja 3, n. ${ }^{\circ} 10$.

1586, julio, 18, parroquia de san Pedro, Valencia.

Felipe II concede a su lugarteniente, Francisco de Moncada, facultad para mediar en el pleito existente entre la ciudad de Alicante y Muchamiel. Éste consiste en que Muchamiel debe de pagar a Alicante 3.500 sólidos por año, en dos pagos, en los meses de marzo y abril, como censo de sus propiedades. Muchamiel recusa este impuesto pero la nueva sentencia es favorable a Alicante y se obliga a pagar a Muchamiel la cantidad de 1.000 libras anuales.

A.-A. M. A. Caja 3, n. ${ }^{\circ} 11$.

1587, diciembre, 24, Madrid.

Felipe II confirma la sentencia dada por él en 1581, en el pleito presentado por el fiscal y procurador de nuestro patrimonio y el síndico de la ciudad de Alicante, ratificando dicha sentencia en favor del síndico.

A.-A. M. A. Caja 5, n. ${ }^{\circ} 23$.

E.-A. M. A. Armario 1, libro 3, fol. 250v a 251v.

1589, enero, 15, Madrid.

Felipe II concede a Pedro de Torres el oficio de racional de la ciudad de Alicante por un trienio, recibiendo por este servicio un justo salario, las ganancias, emolumentos, gracias y honores que dicho trabajo conlleve.

A.-A. M. A. Caja 3, n. ${ }^{\circ} 12$.

35

1589, junio, 14, parroquia de san Pedro, Valencia.

Felipe II ante el leito presentado por los pescadores y los justicias, jurados y ediles de Alicante, declara la sentencia favorable a los primeros, ya que los privilegios y provisiones que etos alegaban fueron concedidos por Carlos I el 9 de mayo de 1520.

A.-A. M. A. Caja 3, n. ${ }^{\circ} 13$.

E.-A. M. A. Armario 1, libro 3, fol. 236v a 239. 
1590, marzo, 22, parroquia de san Gil, Madrid.

Felipe II ante el pleito presentado entre el síndico de la ciudad de Alicante y Pedro Morales, junto con otros compañeros, declara la sentencia favorable al primero, ya que para poder desempeñar los oficios de justicias, jurados y ediles, deben de ser insaculados en el saco mayor y en el menor se insaculan los oficios de cequiero y clavario.

$$
\text { A.-A. M. A. Caja 3, n. }{ }^{\circ} 14 .
$$

1591, enero, 26, parroquia de san Pedro, Valencia.

Felipe II ante el pleito presentado por el sindico de Alicante contra Muchamiel, declara la sentencia contraria a Muchamiel y se le obliga a pagar la cantidad de 2.000 sólidos anuales, como ya había sido sentenciado el 18 de julio de 1586 y aún no la habian cumplido.

A.-A. M. A. Caja 3, n. ${ }^{\circ} 16$.

E.-A. M. A. Armario 1, libro 3, fol. 193v a 198.

1591, octubre, 21, Valencia.

Felipe II concede a los justicias, jurados y síndicos de Alicante el poder cargar a la ciudad con 6.000 libras para asi poder restituir y mejorar los trabajos relacionados con el trigo, puesto que la gran esterilidad de éste se extiende a todo el reino y urge el que se tomen medidas.

B.-Inserto en el documento $n .^{\circ} 39$.

1591, noviembre, 13, Valencia.

Felipe II copia un documento dado por él en octubre de 1591 por el cual concede a los justicias, jurados y síndicos de la ciudad de Alicante el cargas a dicha cidad con 6.000 libras para poder restituir y mejorar los trabajos relacionados con el trigo.

C.-A. M. A. Caja 3, n. ${ }^{\circ} 17$.

1592, mayo, 8, Valencia.

Felipe II concede en este privilegio que ningún comerciante extranjero desconocido en la ciudad de Alicante pueda comprar esparto a los esparteros de la misma y estos sólo lo podrán hacer si pagan en invierno un precio mínimo de 10 sólidos y en verano de 12 sólidos. En caso de incumplimiento se pagarán 1.000 florines de oro de Aragón que pasarán a las arcas reales.

B. - Inserto en el documento $n .^{\circ} 44$.

E.-A. M. A. Armario 1, libro 3, fol. 233v a 234.

E1.-A. M. A. Armario 1, libro 3, fol. 235v a 236. 
1594, enero, 25, Madrid.

Felipe II concede al doctor Luis Berenguer el nombramiento del oficio de abogado fiscal y patrimonial de la ciudad de Alicante, el cual percibirá por su trabajo el salario, el lujo, las ganancias, los privilegios y las gracias que deriven del mismo.

A.-A. M. A. Caja 3.

42

1594, julio, 20, monasterio de san Lorenzo.

Felipe li da licencia a los administradores de la obra pía que instituyó y fundó Pedro de Castroverde para poder amortizar 1.549 libras, 5 sueldos y 9 dineros en moneda valenciana, pagando la cuarta parte del derecho de amortización.

A.-A. M. A. Caja 3, n. ${ }^{\circ} 25$.

1594, agosto, 13, monasterio de san Lorenzo.

Felipe II concede licencia y facultad para amortizar a la ciudad de Alicante 1.000 libras anuales, para la dotación de la iglesia colegial que se ha de construir en la misma.

A.-A. M. A. Caja 3, n. ${ }^{\circ} 24$.

E.-A. M. A. Armario 1, libro 3, fol. $204 \mathrm{v}$ a $206 \mathrm{v}$.

44

1594, agosto, 27, monasterio de san Lorenzo.

Felipe II concede a la ciudad de Alicante el poder tener las asesorías de gobernador y baile general, éstas estaban en Orihuela y en Alicante sólo habian unas dependencias. Ahora cuando estas dos asesorias vaquen en Orihuela se elegirán cargos independientes para las dos ciudades y recibirán por dichos oficios los mismos sueldos.

A.-A. M. A. Caja 3, n. ${ }^{\circ} 25$.

E.-A. M. A. Armario 1, libro 3, fol. $222 \mathrm{v}$ a $223 \mathrm{v}$.

1594, noviembre, 20, Madrid.

Felipe II concede licencia para adquirir a los jurados administradores de Alicante 1.500 libras valencianas en bienes, para el hospital de la ciudad, pero de dicha cantidad deja libre la cuarta parte de los derechos de amortización por el amor y la caridad hacia Dios, pero las otras tres partes son para devolverlas.

A.-A. M. A. Caja 3, n. ${ }^{\circ} 22$.

G.-A. M. A. Armario 1 , libro 7 , fol. $38 \mathrm{v}$ a 39 . 
1595, julio, 26, monasterio de san Lorenzo.

Felipe II concede el oficio de racional a Gaspar Fernández de Mesa, duradero para el primer trienio, recibiendo por éste el salario, lujo, ganancias, privilegios y gracias que se deriven de la realización del mismo.

A.-A. M. A. Caja 3, n. ${ }^{\circ} 27$.

1596, febrero, 6, Madrid.

Felipe II confirma el privilegio de 8 de mayo de 1592, otorgado por él a la ciudad de Alicante, en el cual se explica que no se debe de vender el esparto a comerciantes desconocidos ysólo lo podrán vender si estos pagan por él 10 sólidos en invierno y 12 en verano.
A.-A. M. A. Caja 3, n. ${ }^{\circ} 26$.
E.-A. M. A. Armario 1, libro 3, fol. 233 a 235.

48

1596, agosto, 27, Valencia.

Felipe II junto con los justicias, jurados y el consejo de la ciudad de Alicante, decretan el cargar a la ciudad con 6.000 libras en monedas, de las cuales 3.000 serán para reparar y de nuevo fortificar los muros del Castillo de dicha ciudad, para asi defenderlo de los infieles y las otras 3.000 para reparar los muros de la ciudad.
A.-A. M. A. Caja 3, n. ${ }^{\circ} 29$.

1598, junio, 20, Madrid.

Felipe II decide ampliar por otro trienio el oficio de racional de la ciudad de Alicante a Gaspar Fernández de Mesa, para así poder seguir en dicho oficio cuando se le acabe el trienio que se le concedió el 27 de agosto de 1596.

A.-A. M. A. Caja 3, n. ${ }^{\circ} 30$.

\section{0}

1599, octubre, 12, parroquia de santa Cruz, Valencia.

Felipe III ante la denuncia presentada por Nicolás López contra Martín González, acusado de deber a la ciudad de Alicante la suma de 521 libras, 2 sólidos y 5 denarios y de estar a su vez desempeñando el oficio de cequiero, declara la sentencia favorable a Nicolás López y obliga a Martín González a dejar el oficio que desempeña ya que no pueden ocupar oficios públicos todas aquellas personas que deban algo a la ciudad.

A.-A. M. A. Caja 3, n. ${ }^{\circ} 34$. 
1602, agosto, 21, en el Palacio Real de Valencia.

Felipe III concede licencia y facultad a la ciudad de Alicante y a sus oficiales para cargar 20.000 libras en censos para la reedificación y restauración del pantano.

B.- Inserto en el documento $n .^{\circ} 52$.

1602, noviembre, 13, Alicante.

Felipe III copia el privilegio dado por él el 21 de agosto de 1602, por el cual concede licencia para poder cargar a la ciudad de Alicante 20.000 libras en censos para así poder reedificar y restaurar el pantano.

C.-A. M. A. Caja 4.

53

1604, octubre, 1, parroquia de san Pedro, Valencia.

Felipe III ante el proceso presentado por Marco Antonio Pascual de Bananca, por ser enviado a una reunión real, como representante de la ciudad de Alicante, para resolver algunos negocios y le fueron asignados para sus gastos la cantidad de 33 reales béticos diarios, pero él sobrepasó dicha cantidad y se gastó 13.856 dragmas béticas, pidiendo ahora no devolverlas. Pero la sentencia del rey no le es favorable, condenándole así a pagar 700 libras, mandándole a los oficiales correspondientes para su cobro.

A.-A. M. A. Caja 4, n. ${ }^{\circ} 8$.

54

1604, noviembre, 19, parroquia de san Pedro, Valencia.

Felipe III ante el proceso presentado para reformar las bolsas insculatorias, declara: que para poder desempeñar los oficios públicos en la ciudad de Alicante, se deben reunir las cualidades necesarias, por lo tanto en la bolsa de mano mayor sólo deberán ser insaculados los que las reunan, aunque no sean nobles, ya que muchos aun siéndolo no deben de permanecer en dicha bolsa sino en la de mano menor.
A.-A. M. A. Caja 4, n. ${ }^{\circ} 9$.
E.-A. M. A. Armario 1, libro 3, fol. $263 \mathrm{v}$ a $268 \mathrm{v}$.

1605, febrero, 8, Domo de Ventosilla.

Felipe III concede a los jurados de Alicante la facultad de nombrar a Tomás Bernabé para el oficio de custodio del pantano, sus aguas, acequias y su acueducto, sustituyendo a Jerónimo Rodrigo, que dejó vacante dicho puesto. Por la realización de dicho trabajo le conceden un salario, asi como las prerrogativas e inmunidades que de él se deriven.

$$
\text { A.-A. M. A. Caja 4, n. }{ }^{\circ} 10 .
$$


1605, abril, 16, Valencia.

Felipe III manda hacer expedir esta carta para que Nicolás Dezllor, notario y síndico de Alicante, pueda realizar la ejecución de la real sentencia de 19 de noviembre de 1604 sobre las insaculaciones, en la manera y modo que alli estén contenidos.

A.-A. M. A. Caja 4, n. ${ }^{\circ} 9$.

1605, mayo, 5, Alicante.

Pedro Domenech y otros caballeros de Alicante, estando en contra de la reforma de los sacos del 19 de noviembre de 1604 y de la real ejecución de 16 de abril de 1604, desean que sean puestos los nombres de Pedro Domenech y Francés Domenech Germán en el saco de caballeros y que se extraiga de él a Miguel Serrano, Miguel Nadal y Jaime Pastor, notificándoles si desean ser insaculados en el saco de mano mayor.

A.-A. M. A. Caja 4, n. $^{\circ} 9$.

E.-A. M. A. Armario 1, libro 3, fol. 270 a $270 \mathrm{v}$.

58

1605, agosto, 17, parroquia de san Pedro.

Felipe III ante el pleito presentado por Nicolás Pascual de Baltazar y habiéndose informado que éste reune los méritos militares y las cualidades necesarias $y$ convenientes para poder ser insaculado en la bolsa de mano menor, declara la sentencia favorable al mismo, dándole derecho a poder asi optar a los cargos de justicia, jurado y otros oficios públicos.

A.-A. M. A. Caja 4, n. ${ }^{\circ} 11$.
E.-A. M. A. Armario 1, libro 3, fol. 290 a 292.

59

1605, agosto, 21, parroquia de san Pedro, Valencia.

Felipe III ante el proceso presentado por el síndico de la ciudad de Alicante, exponiendo éste los diversos gastos extraordinarios que ha tenido la ciuadad (muelle y muros), declara el rey la sentencia favorable a ésta, declarando asi que en este año no se paguen las 3.000 libras que debe en censos y se las prolonga hasta 1606.

A.-A. M. A. Caja 4, n. $^{\circ} 12$.

60

1605, noviembre, 5, parroquia de san Pedro, Valencia.

Felipe III ante el proceso presentado por el síndico de la ciudad de Alicante, declara la sentencia favorable de éste, concediendo que las cantidades para limpiar la acequia de la paleta mayor, para la construcción de una caseta para custodiar el pantano y para la reparación de la señal de la paleta, que en un total as- 
cienden a 184 libras, 13 sólidos y 2 denarios, sean pagadas por el clavario Pedro Nogueroles del dinero aumentado para dicho pantano en los censos.

A.-A. M. A. Caja 4.

61

1606, marzo, 17, cerca de la Iglesia de san Bartolomé, Valencia.

Felipe III ante el proceso presentado por Nicolás Desllor, notario, síndico y procurador de la ciudad de Alicante, declara la sentencia favorable a éste, para que el clavario, con el dinero que se le ha dado para el pantano pague a José Galvany Fabro y a Francisco Carbonell, guardas del mismo, sus salarios de 150 libras, y que también pague a los jurados 100 sólidos por sus visitas al mismo.

A.-A. M. A. Caja 4.

62

1607, marzo, 2, parroquia de san Pedro, Valencia.

Felipe III ante el proceso presentado por los justicias, jurados y consejeros de Alicante contra los vecinos de ésta que tienen huertos y que para poder regarlos cometen robos y fraudes en las aguas de riego, debido a la escasez de éstas, declara la sentencia condenatoria para los que cometan dichos fraudes, debiendo pagar estos un tercio de compensación, impuesto por el fisco real y éste pasará al tesoro público.

$$
\text { A.-A. M. A. Caja 4, n. }{ }^{\circ} 14 .
$$

63

1609, abril, 8, parroquia de san Pedro, Valencia.

Felipe III ante el proceso presentado por el síndico y procurador de Alicante, Nicolás Desllor, declara la sentencia favorable a los vecinos de Castalla, Onil y Tibi, para que puedan regar estos en las tierras que hasta entonces no lo hacían, mandando asi al clavario del pantano que deje en libertad las aguas que estaban en reserva para asi poder realizar estos nuevos riegos.

A.-A. M. A. Caja 4, n. ${ }^{\circ} 15$.

64

1617 , diciembre, 16, parroquia de san Juan, Madrid.

Felipe III ante el proceso presentado por el síndico de la ciudad de Alicante en contra del de la ciudad de Orihuela, declara la sentencia favorable al primero, concediendo así que los lugartenientes y gobernadores de más allá de Jijona, no puedan ejercer el oficio de lugartenientes en Alicante en los lugares de dicha gobernación.
A.-A. M. A. Caja 4 , n. ${ }^{\circ} 16$.
G.-A. M. A. Armario 1, libro 7, fol. 20 a $21 \mathrm{v}$. 
1623, julio, 20, calle de Predicadores, Valencia.

Felipe IV ante el proceso presentado por Alfonso Pascual y Juan Roselló, notarios y síndicos de la ciudad de Alicante, declara la sentencia favorable a ésta, por la cual se le permite nuevamente arrendar en censos los derechos sobre la carne y la debada, por la cantidad de 3.000 libras anuales, teniéndolas que devolver en tres quadrienios.

A.-A. M. A. Caja 5, n. ${ }^{\circ} 1$.

66

1626, septiembre, 19, parroquia de san Estéfano, Valencia.

Felipe IV ante el proceso presentado por Pedro Macia, procurador, declara la sentencia favorable a Adrián Riera y Estéfano Berenguer, ciudadanos de Alicante, ya que, tras haber sido estudiada su procedencia y titulación, reunen las cualidades necesarias para poder ocupar cargos públicos y por lo tanto poder ser insaculados en la bolsa mayor.

A.-A. M. A. Caja 5, n. 2.

G.-A. M. A. Armario 1, libro 7, fol. 125 a 126v.

1627, febrero, 1, Valencia.

Felipe IV manda que se ejecute la sentencia de 10 de septiembre de 1626, en la cual Adrián Riera y Estéfano Berenguer pueden ser insaculados en la bolsa o saco mayor de ciudadanos, para los oficios que los ciudadanos honrados suelen desempeñar.

A.-A. M. A. Caja 5, n. $^{\circ} 2$.

G.-A. M. A. Armario 1, libro 7, fol. 126v a 127.

1627, mayo, 11, parroquia de san Esteban, Valencia.

Felipe IV ante el proceso presentado por Alejandro Bonari, ciudadano de mano mayor, hijo de Sebastián Bonari, para que se le fueran reconocidos sus méritos y así ser insaculado en la bolsa de mano mayor, como ya lo habia sido en tiempos pasados su abuelo, es por lo que declara la sentencia favorable a éste, reconociéndole sus dotes óptimas para su insaculación en dicha bolsa.

A.-A. M. A. Caja 5, n. ${ }^{\circ} 3$.

1634, julio, 13, Valencia.

Felipe IV decreta que se carguen en censal 2.333 libras, 6 sólidos y 8 denarios a la ciudad de Alicante para la construcción de una esclusa. Para el pago de este censo deberá de vender algunas propiedades, asi como cargar una cantidad sobre los frutos de la tierra.
A.-A. M. A. Caja 5, n. ${ }^{\circ} 6$. 
1635, junio, 15, parroquia de san Juan, Madrid.

Felipe IV ante el proceso presentado entre el síndico de la ciudad de Alicante y Marco Antonio Paravesino, declara la sentencia favorable a este último, debiéndosele así confirmar sus méritos.

A.-A. M. A. Caja 5, n. ${ }^{\circ} 7$.

1635, noviembre, 20, Madrid.

Felipe IV concede a Francisco Martínez de Fresnada, noble de esta ciudad, el oficio de racional de la ciudad de Alicante, por un trienio, cargo que debe de ser desempeñado por un noble, recibiendo por este trabajo el sueldo, lujos, emolumentos, prerrogativas y honores que del mismo deriven.

A.-A. M. A. Caja 5, n. $^{\circ} 8$.

G.-A. M. A. Armario 1, libro 7, fol. 313 a $313 \mathrm{v}$.

72

1636, abril, 28, parroquia de san Pedro, Valencia.

Felipe IV ante el proceso iniciado por Pedro Linares, ciudadano de la ciudad de Alicante, para que le fuera reconocido su derecho a ser introducido en la bolsa de ciudadanos de mano mayor de esta ciudad para su insaculación y comprobando el monarca que así debía de ser, declara la sentencia favorable a Pedro Linares, dándole así el privilegio de ser insaculado.

A.-A. M. A. Caja 5, n. ${ }^{\circ} 9$.

1637, julio, 7, Madrid.

Felipe IV ante la muerte de Francisco Martínez de Fresnada, racional de la ciudad de Alicante, y vacar este puesto que lo debía de ocupar desde el 20 de noviembre de 1635 hasta noviembre de 1638, es por lo que concede a Tomás Pascual el poder desempeñar dicho cargo hasta que se cumpla el trienio que tenía otorgado Francisco Martínez de Fresneda, recibiendo por el cumplimiento de mismo el salario, los lujos, honores y prerrogativas que de él deriven.

A.-A. M. A. Caja 5, n. ${ }^{\circ} 4$.

1639 , julio, 8, parroquia de san Juan, Valencia.

Felipe IV ante el proceso interpuesto por Vicente Pina, procurador de Jacobo Pina, ciudadano de Alicante, para que le fuese reconocido el poder insacularse en la bolsa de ciudadanos de mano mayor y tras comprobar los méritos de éste, el monarca declara la sentencia favorable a Jacobo Pina, pudiendo así ser insaculado en la bolsa de ciudadanos de mano mayor.

A.-A. M. A. Caja 5, n. ${ }^{\circ} 25$. 
1642, febrero, 25, Madrid.

Felipe IV concede a Juan Bautista Paravesino, el oficio de racional de la ciudad de Alicante por un trienio, recibiendo por su cumplimiento el sueldo, lujos, emolumentos, prerrogativas y honores que del mismo deriven.
A.-A. M. A. Caja 5, n. ${ }^{\circ} 11$.
G.-A. M. A. Armario 1, libro 7, fol. 331v a 332 .

\section{6}

1644, noviembre, 5, parroquia de san Juan, Valencia.

Felipe IV ante el proceso presentado por el notario Andrés Miguel, representante de Mateo y Santiago Cantó, ciudadanos de Alicante, para que se les fueran concedidos sus derechos a ser insaculados en la bolsa de mano mayor y viendo el monarca que reunen las condiciones necesarias, declara la sentencia a favor de los hermanos Cantó, pudiendo así ser insaculados en dicha bolsa mayor.

A.-A. M. A. Caja 5, n. ${ }^{\circ} 12$.

1644, diciembre, 4, Madrid.

Felipe IV concede a la ciudad de Alicante que el oficio de racional, que hasta ahora era electivo y duradero para tres años, pase a ser de extracción, es decir, que se introduzca en la bolsa de los oficios de mano mayor, un año en la de ciudadanos y el siguiente en la de caballeros, empezando por la de ciudadanos, ya que quien ahora desempeña dicho oficio es un caballero. También pasa dicho oficio a ser de duración anual, como todos los demás.

A.-A. M. A. Caja 5, n. ${ }^{\circ} 13$.

G.-A. M. A. Armario 1, libro 7, fol. 347 a $348 \mathrm{v}$.

1647, septiembre, 3, Madrid.

Felipe IV concede a la ciudad de Alicante que el baile general y su asesor ordinario de distrito, se intitulen como baile general y asesor ordinario de la ciudad de Alicante del reino de Valencia.

A.-A. M. A. Caja 5, n. ${ }^{\circ} 14$.

G.-A. M. A. Armario 1, libro 7, fol. 356v a $357 \mathrm{v}$.

79

1651, enero, 16, parroquia de san Juan, Madrid.

Felipe IV ante el proceso interpuesto por Santiago Rosell y Desprats, baile general de Alicante, contra el justicia de dicha ciudad por el veredicto dado por el juez a Tomás Arenas, castigándolo por sus crímenes cometidos y viendo el monarca que el justicia de dicha ciudad tenía razón, declara la sentencia a favor del síndico de la ciudad. 
A.-A. M. A. Caja 5, n. ${ }^{\circ} 15$.

G.-A. M. A. Armario 1, libro 7, fol. 367 a $368 \mathrm{v}$.

80

1651, mayo, 26, Madrid.

Felipe IV ante la sentencia dada el 16 de enero de 1651 a favor del justicia de la ciudad de Alicante y en contra de Santiago Rosell y Desprats, baile general de la ciudad de Alicante, es por lo que para su real ejecución manda a Vicente Maynar que haga lo oportuno para que dicha sentencia se cumpla.

A.-A. M. A. Caja 5, n. ${ }^{\circ} 16$.

1655, mayo, 23, Madrid.

Felipe IV concede a la ciudad de Alicante el que se pueda insacular en la bolsa de caballeros a los nobles que reunan las mismas cualidades y condiciones que estos y asi puedan acceder a los oficios de la gobernación.

A.-A. M. A. Caja 5, n. ${ }^{\circ} 17$.

F.-A. M. A. Armario 1, libro 4, fol. 27 a 28.

1661, mayo, 10, Valencia.

Felipe IV concede a la ciudad de Alicante y a la villa de Muchamiel el poder cargarse 2.000 libras a censal para asi acabar las obras necesarias en la iglesia de san Nicolás y santa María y hacer un sagrario en el convento de la santa Verónica, que es la patrona de dicha ciudad. La amortización del censo se hará con los 8 dineros que se cobraban de sisa en cada libra de carne.

A.-A. M. A. Caja 5, n. ${ }^{\circ} 18$.

83

1674, octubre, 16, Valencia.

Carlos II constituye y crea una notaría para Jacobo Garriga, notario público en todo el reino de Valencia.

A.-A. M. A. Caja 5, n. ${ }^{\circ} 19$.

1675 , enero, 2, Valencia.

Carlos II constituye y crea una notaría para Francisco Rodrigo, notario público en todo el reino de Valencia.

A.-A. M. A. Caja 5, n. 20.

1675, enero, 21, Valencia. 
Carlos II concede a la ciudad de Alicante 500 libras en limosna para ayudar en los gastos de la canonización del padre san Pascual Baylón.

A.-A. M. A. Caja 5, n. ${ }^{\circ} 21$.

86

1679, julio, 15, Valencia.

Carlos II constituye y crea una notaría para Antonio Soler, notario público en todo el reino de Valencia.

A.-A. M. A. Caja 5, n. 22.

87

1683, diciembre, 7, Valencia.

Carlos II confirma la deliberación adoptada por el consejo general de Alicante el 15 de enero de 1682, consistente en aprobar que se haga un retablo nuevo para la iglesia parroquial de san Juan y Benimagrell, y que éste se pague: la mitad de las rentas y regalías de dicha universidad y la otra mitad se obtendrá al cargar 2 dineros sobre cada libra de carne.

A.-A. M. A. Caja 5A, n. ${ }^{\circ} 25$. 